\title{
A meta-analysis and experiment assessing phage-based FMDV vaccine
}

2 Peng $\mathrm{Wu}^{1,3,4} \boldsymbol{\pi}$, Ningning Yang ${ }^{2,3,4}$ 爪, Yueli $\mathrm{Wang}^{2,3,4} \pi$, Mingguo $\mathrm{Xu}^{2,3,4}$, Yunfeng

3 Zhang ${ }^{2,3,4,5}$, Chuangfu Chen $2,3,4^{*}$

$4 \quad{ }^{1}$ College of Animal Sciences, Shihezi University, Shihezi, Xinjiang, China

$5{ }^{2}$ School of Animal Science and Technology, Shihezi University, Shihezi, Xinjiang,

6 China

$7 \quad{ }^{3}$ Co-Innovation Center for Zoonotic Infectious Diseases in the western region, Shihezi,

8 Xinjiang, China

$9 \quad{ }^{4}$ Key Laboratory of Control and Prevention of Animal Disease, Xinjiang Production \&

10 Construction Corps, Shihezi, Xinjiang, China

115 State Key Laboratory of Sheep Genetic Improvement and Healthy Production/

12 Xinjiang Academy of Agricultural and Reclamation Sciences, Xinjiang, China

$13 *$ Corresponding author: ccf@shzu.edu.cn (CC)

14 T These authors contributed equally to this work

15 Abstract: Foot-and-mouth disease (FMD) is a pathological disease caused by the footand-mouth disease virus (FMDV), which mainly affects cloven-hoofed animals. This

17 study was conducted to a meta-analysis and experiment on the effect of bacteriophages

18 used in the development of FMDV vaccines. A systematic search was conducted for

19 the collection of the protection effect for the phage-based FMDV vaccine using

20 sensitive search strategies. The extracted data were analyzed using Rev-Man 5.4

21 software. This experiment used the T7 phage to express the capsid protein VP1 of the

22 OHM-02 strain, and the recombinant VP1 phage was termed OHM-T7. Antibodies and 
cytokines levels were assessed after immunizing BALB/C mice with OHM-T7. The results showed that a total of 115 articles were retrieved, and 4 of them met the inclusion criteria. There was no heterogeneity with $\mathrm{I}^{2}=0 \%, 20 \%$ or $43 \%$. We used a fixed-effect model for meta-analysis, and the results showed a protective effect on FMDV between the phage group and control group $(P<0.01)$ and between FMDV group and control group $(P<0.01)$. Furthermore, when the phage group was compared to the FMDV group, there was also no significant difference $(P>0.05)$. After successfully obtained the ohmt7 strain and immunized the mice, it could induce high levels of IFN- $\gamma$ levels in mice with little effect on IL-4 levels. OHM-T7 could be used to detect antibodies produced by mice immunized with different FMDV antigens and produce high levels of antiFMD antibodies. In summary, these results showed the potential of phage-based FMDV vaccines in FMDV prevention.

\section{Introduction}

Foot-and-mouth disease (FMD) is a pathological disease caused by the foot-and-mouth disease virus (FMDV), which affects cloven-hoofed animals [1,2]. FMD causes serious economic and social problems, and is listed as a legally reportable disease by the World Organization for Animal Health (OIE) [3]. The virus has no capsule and has a diameter of about $30 \mathrm{~nm}$. FMDV can infect cloven-hoofed animals, including pigs, sheep, goats, cattle and diverse wildlife species, and remains a major threat to the livestock industry worldwide [4]. Cattle could spread FMDV to pigs [5]. O-type FMDV is the most popular subtype around the globe. Currently, there is no vaccine that could protect animals from all serotypes [6]. Therefore, new vaccines are urgently needed to prevent 
the spread of FMD [7]. The capsid protein VP1 of FMDV is a sequence-dependent epitope, is the main antigenic site of FMDV, and can induce neutralizing antibodies. Microphage (Phage) has been researched for decades [8]. Smith confirmed in 1985 that exogenous DNA could be inserted into the filamentous phage gene III and fused to the pIII protein [9]. The phage display technology inserts a DNA sequence into the phage coat protein's structural gene, allowing the foreign gene to be expressed along with the coat protein [10-12]. Studies have shown that phages can be used to simulate viral epitopes $[13,14]$. The asymmetry of phage can enhance the immune response of helper T cell- 1 and cause $\mathrm{CD}^{+} \mathrm{T}$ cells to secrete cytokines $[15,16]$. The current phage display technology can insert DNA sequences into the structural genes of phage coat proteins so that foreign genes and coat proteins can be expressed together [10,12,17]. Phage display technology has been shown to increase the stability and immunogenicity of the antigen [18-20]. The phage display system is an ideal B cell epitope display vector and recombinant virus-like particles (VLPs) [21]. Among them, VLPs were found to be as immunogenic as the native virus, and the main reason for this is that the capsids are more heat-labile [22]. Therefore, phage vaccine, as a particulate antigen, can be quickly taken up by antigen presenting cells (APC). VLPs showed high immunogenicity and are easily recognized by the immune system [23]. Phage particles can also induce a strong cellular immune response [15]. Related studies have found that the peptides displayed by T7 phage bind closely to FMD serum [24]. To develop an effective FMD vaccine, we here conducted a meta-analysis and used a phage to display the FMD VP1 protein. 
67

68

\section{Materials and Methods}

\section{Literature search strategy}

The literature retrieved in this meta-analysis was evaluated before March 2020 by two researchers. The National Library of Medicine (Medline via PubMed), Embase, China National Knowledge Infrastructure (CNKI), and Wan fang DATA were searched for phage-based FMDV vaccines, using the keywords "FMDV," "phage," and "vaccine." Inclusion and exclusion criteria

We used the following inclusion criteria: (1) Published documents included Chinese and English literature. (2) FMDV was expressed by the phage vector. (3) The protective effect of FMDV was evaluated in terms of the lethal dose. We used the following exclusion criteria: (1) Method dissimilar to FMDV vaccine. (2) The carrier was not a phage. (3) The results did not provide the necessary basic data.

Data extraction tired

The two researchers conducted a preliminary screening by reading the titles and abstracts of the previous studies, then read the full text and made their selection according to the inclusion and exclusion criteria. If there were differences of opinion, we had already discussed and solved them. We independently extracted the data. The data extracted included the first author, publication time, events, and total number of animals in the trials.

Analysis of extracted data

The database was developed using Excel. RevMan 5.4 software was used in this metaanalysis to perform the statistical analyses. The fixed-effect model was used for meta- 
89

90

91

92

93

94

analysis to calculate the odds ratios (OR), together with a 95\% confidence interval (CI)

for dichotomous results. ORs were used to evaluate the difference in immunogenicity between the two groups. A OR=1 indicates that data is of no worth. OR above 1.0 correspond to an effect favoring vaccination. Statistical heterogeneity between the studies was assessed using the $\mathrm{I}^{2}$ statistic and Q statistic. $P \geq 0.05$ or $\mathrm{I}^{2} \leq 50 \%$ indicated that the trials were free of heterogeneity, and a fixed-effect model was used to perform the meta-analysis. $\mathrm{I}^{2}>50 \%$ led us to consider a random-effect model to perform the meta-analysis. Where applicable, we presented results from individual trials and the common effect estimate in a forest plot. Squares indicate individual study odds ratios together with their $95 \%$ CI indicated as bars. Sensitivity analysis was performed using the difference of the combined values of the model effects, and the funnel plot method was used to evaluate the publication bias of the included works.

Evaluation of the quality of evidence

All of the included studies were animal experiments, and animal experiments may be the highest level of evidence.

Construction of the recombinant vector

The VP1 gene plasmid of OMH-02 was doubles digested using EcoR I and Hind III (TaKaRa, Dalian, China). In the control group, no enzyme was added; in the negative control group, the enzyme was substituted by an equal volume of water. All samples were incubated in a water bath at $37^{\circ} \mathrm{C}$ for $4 \mathrm{~h}$. The digested product was subjected to $1 \%$ agarose gel electrophoresis. The target band was excised and purified with a DNA gel recovery kit (TaKaRa, Dalian, China), according to the manufacturer's instructions. 
The extracted fragment of interest was ligated into the T7Select ${ }^{\circledR}$ vector in a reaction

112 (Merck KGaA, Darmstadt, Germany). The sample was added to a $1.5 \mathrm{~mL}$ EP tube,

113 gently pipetted up and down, incubated at $16^{\circ} \mathrm{C}$ for $16 \mathrm{~h}$, and stored at $4^{\circ} \mathrm{C}$.

114 Phage packaging and plaque assay

115 The T7Select ${ }^{\circledR}$ package extract was thawed on ice. Then, $5 \mu \mathrm{L}$ of the extract was added 116 to $5 \mu \mathrm{L}$ of the ligation reaction. The mixture was reacted at $22^{\circ} \mathrm{C}$ for $2 \mathrm{~h}$, and $270 \mu \mathrm{L}$ 117 of TB medium was added. The phage was supplemented to E.coli BLT5403 in the 118 logarithmic growth phase, and cultured at $37^{\circ} \mathrm{C}$ for 3 h. E.coli BLT5403 strain was 119 inoculated in M9TB medium and incubated at $37^{\circ} \mathrm{C}$ with shaking to $\mathrm{OD}_{600}=1.0$. Molten 120 agarose was incubated in a water bath at $50^{\circ} \mathrm{C}$. A $10^{3}-10^{6}$ diluted sample was prepared 121 with sterile TB medium as a diluent. Next, 250 microliters of BLT5403 was added to 122 the EP tube, followed by addition of $100 \mu \mathrm{L}$ of phage dilution and $3 \mathrm{~mL}$ of top agarose.

123 The mixture was poured into an agar plate, inverted and incubated at $37^{\circ} \mathrm{C}$ for $4 \mathrm{~h}$. The 124 plaques were counted, and phage titers were determined.

126 A single plaque was scraped off using a pipette tip and heated at $65^{\circ} \mathrm{C}$ for $10 \mathrm{~min}$. The 127 sample was cooled to room temperature and centrifuged at $14,000 \times \mathrm{g}$ for $3 \mathrm{~min}$. Primers were: T7 Select-F 5'-GGAGCTGTCGTATTCCAGTC-3'and T7 Select-R 5'- 
FMD serum samples were diluted 30 -fold with the ELISA coating solution, and $100 \mu \mathrm{L}$

134 was added per well of the ELISA plate, which was incubated overnight at $4^{\circ} \mathrm{C}$. After

two washes with PBST, $200 \mu \mathrm{L} /$ well of 5\% skim milk powder was added and incubated

at $37^{\circ} \mathrm{C}$ for $2 \mathrm{~h}$. The plates were washed 3 times with PBST, and OHM-T7 was added

137 for $2 \mathrm{~h}$ at $37^{\circ} \mathrm{C}$. The cells were washed 3 times with PBST, and BLT5403 cells in the

138 logarithmic growth phase were added to the wells and cultured in a $37^{\circ} \mathrm{C}$ incubator for

$1391 \mathrm{~h}$. The bacterial suspension was aspirated and added to $20 \mathrm{~mL}$ of BLT5403 culture in

140 the logarithmic growth phase, cultured at $37^{\circ} \mathrm{C}$ for $2 \mathrm{~h}$. The library was preserved, and

141 the product was used for subsequent screening. The above experiment was repeated 3

142 times.

143 Immunization of mice

144 Twenty-four female BALB/C mice were purchased from Huaxing Laboratory Animal

145 Farm (Huiji Distract, Zhengzhou, China). All the experimental procedures involving

146 animals were approved by the Animal Experimental Ethical Committee Form of the

147 First Affiliated Hospital of Medical College, Shihezi University (No. A 280-163-01).

148 Female $\mathrm{BALB} / \mathrm{C}$ mice were divided into the $\mathrm{NaCl}$ group, prokaryotic group and phage

149 group, with 8 mice in each group. In the $\mathrm{NaCl}$ group, 250 microliters of normal saline

150 were injected. The OHM-02 VP1 group was injected with prokaryote-expressed FMD

151 VP1 protein at $200 \mu \mathrm{g} /$ mice in a volume of 250 microliters. The OHM-T7 group was

152 injected with $250 \mu \mathrm{L}$ of OHM-T7 at a titer of $4 \times 10^{11}$ Colony-Forming Units (CFU).

153 Serum was collected at $0,14,28,42,56,70,84$ and $98 \mathrm{~d}$, respectively, and antibody

154 levels were measured by ELISA. The OHM-T7 titer was $4 \times 10^{11} \mathrm{CFU}$, and the sample 
was diluted 200-fold with the ELISA coating solution. IL-4 and IFN- $\gamma$ were detected using an ELISA kit (Solarbio, Beijing, China).

The results of ELISA were analyzed with the SPSS 17.0 software (SPSS, Inc. Chicago, performed at least three times.

\section{Results}

\section{Identified study reports}

As shown in Fig. 1, document retrieval and filtering. A total of 115 articles were

167 abstract, a total of 23 articles met the inclusion criteria. In the included literature, a total

168 of 4 articles were included for meta-analysis.

Fig. 1. Flowchart of included and excluded trials.

171 Characteristics of the reports

172 The characteristics of the included study are shown in Table 1. We also noted that all

173 the studies were conducted between 2007 and 2017. 


\begin{tabular}{|c|c|c|c|c|c|c|c|}
\hline \multicolumn{2}{|c|}{ Study } & \multicolumn{2}{c|}{ Phage Group } & \multicolumn{2}{c|}{ Control Group } & \multicolumn{2}{c|}{ FMDV Vaccine Group } \\
\hline Author & Year & Events & Total & Events & Total & Events & Total \\
\hline Dong & 2015 & 3 & 5 & 0 & 5 & 4 & 5 \\
\hline Ren & 2007 & 113 & 164 & 0 & 42 & 15 & 15 \\
\hline Ren & 2015 & 110 & 128 & 0 & 37 & 6 & 6 \\
\hline $\mathrm{Xu}$ & 2017 & 4 & 5 & 0 & 2 & 8 & 10 \\
\hline
\end{tabular}

177 In order to solve the problem of poor test results caused by the small number of

178 documents, we here adopted a combination of statistical values and Q testing. The comparison of immune effects between the control group and experimental group was analyzed by fixed-effect model (Fig. 2).

Fig. 2. Forest plot of meta-analysis for ORR. There was no heterogeneity in this study with $\mathrm{I}^{2}=20 \%, \mathrm{I}^{2}=0 \%$, and $\mathrm{I}^{2}=43 \%$. We used a fixed-effect model for meta-analysis, and the results showed a protective effect on FMDV between the phage group and control group $(\mathrm{MH}=128.09,95 \% \mathrm{CI}=18.95,865.66, P<0.01)(\mathrm{A})$ and between FMDV group and control group $(\mathrm{MH}=160.16,95 \% \mathrm{CI}=14.21,1804.51, P<0.01)(\mathrm{B})$.

187 Furthermore, when the phage group was compared to the FMDV group, there was also no significant difference $(\mathrm{MH}=0.34,95 \% \mathrm{CI}=0.08,1.40, P>0.05)(\mathrm{C})$.

190 The funnel chart method was used to control the publication bias of meta-analysis 191 documents. By observing the funnel chart, we could see that although the pattern was not completely symmetrical, the data were still within the acceptable range (Fig. 3). 
The results showed that the published literature had less publication bias and met the requirements of this study.

Fig. 3. Funnel plot. (A) Phage group vs Control group; (B) Phage group vs FMDV group; (C) FMDV group vs Control group. survival or death, which was very different from the evaluation in humans. agarose gel electrophoresis. The target fragment was about $760 \mathrm{bp}$, which was consistent with the expected size (Fig. 4 A). The OHM-T7 titer was determined (Fig. 4 B). O5, O6 and $\mathrm{O} 7$ plates were $10^{6}, 10^{7}$ and $10^{8}$ times diluted, respectively. Too many

207 plaques grew on plate 5, and plates 6 and 7 had 40 and 4 plaques, respectively, indicating a titer of $(4 \times 108+4 \times 108) / 2=4 \times 10^{8}$. Protein gel electrophoresis showed that

209 OHM-T7 bands could be clearly observed at about $30 \mathrm{kDa}$, which proved that the phage 210 was successfully expressed and purified (Fig. 4 C).

Fig. 4. Construction of OHM-T7. (A) OHM-02 VP1 double restriction. M: DNA

213 Marker 1000; Lanes 1-4: Double enzyme digestion positive clones; Lane 5: control 
T7 control; Lanes 3-4: OHM-T7.

\section{$216 \quad$ Screening}

217 The first round of screening of OHM-T7 on the Figure 5 A-1 plate yielded a titer of $2184 \times 10^{10}$. The titers of the second (Fig. 5 A-2) and third (Fig. 5 A-3) rounds for OHM-T7 219 plate were too high. The results showed that the OHM-T7 was enriched, and that with 220 fast passage ability was selected (Fig. 5 A). The OHM-T7 strain induced high levels of 221 IFN- $\gamma$ levels $(P<0.01)$ in mice with little effect on IL-4 levels $(P>0.05)$.

The difference in anti-OHM-T7 antibody levels between 14 and $0 \mathrm{~d}$ was extremely significant $(P<0.01)$. The results showed that OHM-T7 could quickly induce high levels of antibodies in mice. The difference in anti-OHM-T7 antibody levels between 98 and $2310 \mathrm{~d}$ was also extremely significant $(P<0.01)$. OHM-T7 antibody levels peaked at $98 \mathrm{~d}$. 232 The results showed that OHM-T7 could stimulate mice to produce anti-FMDV 233 antibodies with high titers for a long time (Fig. 6 F). The level of IL-4 remained at a 234 low level with no significant changes. The type II helper T cells (Th2) cells were less 235 active after $14 \mathrm{~d}$ (Fig. 5B). Additionally, mice injected with the OHM-T7 strain had 236 greatly improved levels of IFN- $\gamma$ (Fig. 5C). An increase in IFN- $\gamma$ indicates that type I 
helper T cells (Th1) are activated and IFN- $\gamma$ is a hallmark cytokine of Th1 cells, which

238 function is mainly to promote cellular immunity. This indicates that phage immunity

239 was mainly induced by Th1 cells after $14 \mathrm{~d}$. OHM-T7 could be used to detect antibodies

240 produced by mice immunized with different FMDV antigens (Fig. 6).

Figure 6. Detection of serum antibody levels in mice immunized with different

FMDV antigens by OHM-T7. Blank, a blank control with nothing detected; $\mathrm{NaCl}$,

mouse serum immunized with $0.9 \% \mathrm{NaCl}$; AKT-T7, mouse serum immunized with the

recombinant AKT-III VP1 phage; OHM-T7, mouse serum immunized with the

recombinant OHM-02 VP1 phage; AKT-III VP1, mouse serum immunized with the

III, mouse serum immunized with the AKT-III virus; OHM-02, mouse serum immunized with the OHM-02 virus. The data were analyzed by T-Text using excel

software, $*=P<0.05, * *=P<0.01$.

\section{Discussion}

253 This meta-analysis showed the promise of phage-based FMD vaccines. Bacteriophages

254 have coexisted with humans and animals for a long time, and the safety of using them

255 medically is widely recognized [25]. Recent studies have shown that phages play an

256 important role in the mammalian immune system, and their interaction with mammalian

257 immune cells is of great significance [26].

258 OHM-T7 were screened using immunopositively bovine serum samples, showing 
that the phage could bind to positive sera. After repeated screening, a highly specific

OHM-T7 was obtained. The constructed phage library was reverse-screened, and

OHM-T7 with high binding ability was selected. While obtaining a phage with a strong binding ability, phages with rapid propagation rates were also screened. Within 14 days, the phage could rapidly induce high levels of specific antibodies in the body. The current study only immunized the animals once, but after multiple blood collections the antibody levels remained high, demonstrating that the phage could stimulate the mouse body to maintain high antibody levels for a long time. Antibody levels were highest at 98 days, suggesting that antibody levels may increase. The antibody level of the AKTT7 group was not different from that of the OHM-T7 group. It showed that the phage itself also caused the body to produce high levels of antibodies. The antibody level of the OHM-02 strain was found to be higher than that of the AKT-III group. It showed that OHM-T7 could specifically detect the $\mathrm{O}$ type antibody. It was very strange that the test result of AKT-III VP1 was higher than in the OHM-02 VP1 group. We attributed this to the instability of OHM-02 VP1 protein, and the results found in immunized animals were not ideal. The antibody level produced by the protein of the phage carrier was much higher than the prokaryotic expression. The phage vaccine produced much higher levels of antibodies than the inactivated virus vaccine.

Although we did not evaluate FMDV in animal protection experiments, the literature in the meta-analysis did include such experiments. In this way, our metaanalysis suggested that our recombinant phages may protect animals from FMDV. In 2009, the World Influenza Conference in Europe focused on vaccines for phage-derived 
virus-like particles as delivery vehicles [20]. Phage particle vaccines can also be

282 administered via various immunization routes [26,27]. Under the conditions of large-

283 scale breeding, good oral immunization effects are of great significance for the

284 promotion and use of vaccines [28,29]. The use of a phage as a vector to display specific

285 epitopes of different pathogens can induce a strong immune response in the body [30-

286 33]. Therefore, the phage display technology has its unique value in the development

287 of vaccines.

\section{Conclusion}

289 The results of the present meta-analysis showed that the phage had protective effects

290 on FMDV, and no difference was detected between the FMDV group and control with

291 respect to this protective effect. The OHM-T7 was successfully constructed. OHM-T7

292 could be used to detect antibodies produced by mice immunized with different FMDV

293 antigens and produce high levels of anti-FMD antibodies. This meta-analysis and

294 experiment indicate the potential of phage-based FMDV vaccines in FMDV prevention.

\section{Acknowledgment}

296 This research was funded by CX Collaborative Innovation 2011 Collaborative

297 Innovation Special Project (Grant no. 0101-KC-0003).

\section{Author Contributions}

299 Conceptualization: CC.

300 Data curation: PW, NY, MX, YZ.

301 Formal analysis: PW. NY.

302 Funding acquisition: CC. 
Investigation: MX, YZ.

Methodology: PW, NY, YW.

Project administration: CC.

Resources: CC, PW.

Software: PW, NY.

Supervision: CC, PW.

Validation: CC.

Visualization: MX, YZ.

Writing - original draft: PW.

Writing - review \& editing: PW, NY, Y.W.

\section{References}

1. Niedbalski W, A. Kęsy. Serological differentiation of animals infected and vaccinated against foot-and-mouth disease virus. Med. Weter. 2006; 62: 20-23. https://doi.org/10.1258/002367706775404417.

2. Ryan E, Mackay D, Donaldson A. Foot-and-mouth disease virus concentrations in products of animal origin. Transbound. Emerg. Dis. 2008; 55: 89-98. https://doi.org/10.1111/j.1865-1682.2007.01004.x.

3. Thomson GR, Vosloo W, Bastos ADS. Foot-and-mouth disease in Wildlife. Virus Res. 2003; 91: 145-61. https://doi.org/10.1016/S0168-1702(02)00263-0.

4. Lv J, Ding Y, Liu X, Pan L, Zhang Z, Zhou P, Zhang Y, Hu Y. Gene expression analysis of porcine whole blood cells infected with foot-and-mouth disease virus using high-throughput sequencing technology. Plos One 2018; 13: e0200081. https://doi.org/10.1371/journal.pone.0200081.

5. Mouton Laure, Dekker Aldo, Bleijenberg Meindert, et al. A foot-and-mouth disease SAT2 vaccine protects swine against experimental challenge with a homologous virus strain, irrespective of mild pathogenicity in this species. Vaccine; 2018, 36: 2020-2024. https://doi.org/10.1016/j.vaccine.2018.02.096.

6. Raza S, Siddique K, Rabbani M, et al. In silico analysis of four structural proteins of aphthovirus serotypes revealed significant B and T cell epitopes. Microb. Pathog. 2019; 254-262. https://doi.org/10.1016/j.micpath.2019.01.007.

7. Waters R, Ludi A B, Fowler V L, et al. Efficacy of a high-potency multivalent foot-and-mouth disease virus vaccine in cattle against heterologous challenge with a field virus from the emerging A/ASIA/G-VII lineage. Vaccine 2018; 1901-1907. 
https://doi.org/10.1016/j.vaccine.2018.02.016.

8. Comeau A M, Krisch H M. The Capsid of the T4 Phage Superfamily: The Evolution, Diversity, and Structure of Some of the Most Prevalent Proteins in the Biosphere. Molecular Biology \& Evolution. 2008; 25: 1321-1332. https://doi.org/10.1093/molbev/msn080.

9. Smith G P. Filamentous Fusion Phage: Novel Expression Vectors that Display Cloned Antigens on the Virion Surface. Science 1985; 228: 1315-1317. https://doi.org/10.1126/science.4001944.

10. Bao Q, Li X, Han G, et al. Phage-based vaccines. Adv. Drug Deliv. Rev. 2019; 40-56. https://doi.org/10.1016/j.addr.2018.12.013.

11. Pande J, Szewczyk M M, Grover A K. Phage display: Concept, innovations, applications and future. Biotechnol. Adv. 2010; 849-858. https://doi.org/10.1016/j.biotechadv.2010.07.004.

12. Sidhu S S. Phage display in pharmaceutical biotechnology. Curr. Opin. Biotech. 2000; 11: 610-616. https://doi.org/10.1016/S0958-1669(00)00152-X.

13. De Andrade C Y, Yamanaka I B, Schlichta L S, et al. Physicochemical and immunological characterization of chitosan-coated bacteriophage nanoparticles for in vivo mycotoxin modeling. Carbohyd. Polym. 2018; 63-72. https://doi.org/10.1016/j.carbpol.2017.12.063.

14. Iniguez $\mathrm{P}$, Zientara $\mathrm{S}$. Selection of viral epitopes from phage display libraries. Application to diagnosis of equine arteritis virus. REV. MED. VET-TOULOUSE. 2001; 152: 363-371. https://doi.org/10.1038/srep21979.

15. Kolly R, Thiel M A, Herrmann T, et al. Monovalent antibody scFv fragments selected to modulate T-cell activation by inhibition of CD86-CD28 interaction. PROTEIN. ENG. DES. SEL. 2007; 20: 91-98. https://doi.org/10.1093/protein/gz1058.

16. Yang Q, Wang L, Lu D, et al. Prophylactic vaccination with phage-displayed epitope of C. albicans elicits protective immune responses against systemic candidiasis in C57BL/6 mice. Vaccine 2005; 23: 4088-4096. https://doi.org/10.1016/j.vaccine.2004.07.005.

17. Witherell G W, Gott J M, Uhlenbeck O C. Specific Interaction between RNA Phage Coat Proteins and RNA. Prog. Nucleic Acid Res. 1991; 40: 185-220. https://doi.org/10.1016/S0079-6603(08)60842-9.

18. Massis L M, Braga C J, Sbrogioalmeida M E, et al. Anti-flagellin antibody responses elicited in mice orally immunized with attenuated Salmonella enterica serovar Typhimurium vaccine strains. Mem. I. Oswaldo Cruz 2008; 103: 606-610. https://doi.org/10.1590/S0074-02762008000600017.

19. Larralde O G, Martinez R, Camacho F, et al. Identification of hepatitis A virus mimotopes by phage display, antigenicity and immunogenicity. J. Virol. Methods 2007; 140: 49-58. https://doi.org/10.1016/j.jviromet.2006.10.015.

20. Silman, Nigel J. World Influenza Congress Europe 2009. Expert Rev. Vaccines 2010; 9, 273-275. https://doi.org/10.1586/erv.10.10.

21. Li X, Meng X, Wang S, et al. Virus-like particles of recombinant PCV2b carrying FMDV-VP1 epitopes induce both anti-PCV and anti-FMDV antibody responses. 
Appl. Microbiol. Biotechnol. 2018; 102: 10541-10550. https://doi.org/10.1007/s00253-018-9361-2.

22. Ganji VK, Biswal JK, Lalzampuia H, Basagoudanavar SH, Saravanan P, Selvan RPT, et al. Mutation in the VP2 gene of P1-2A capsid protein increases the thermostability of virus-like particles of foot-and-mouth disease virus serotype $\mathrm{O}$. Appl. Microbiol. Biotechnol. 2018; 102: 8883-8893. https://doi.org/10.1007/s00253-018-9278-9.

23. Samoylova T I, Norris M D, Samoylov A M, et al. Infective and inactivated filamentous phage as carriers for immunogenic peptides. J. Virol. Methods 2012; 183: 63-68. https://doi.org/10.1016/j.jviromet.2012.03.032.

24. Wong C L, Yong C Y, Muhamad A, et al. A 12-residue epitope displayed on phage T7 reacts strongly with antibodies against foot-and-mouth disease virus. Appl. Microbiol. Biotechnol. 2018; 102: 4131-4142. https://doi.org/ 10.1007/s00253-018-8921-9.

25. Aghebati-Maleki L, Bakhshinejad B, Baradaran B, et al. Phage display as a promising approach for vaccine development. J. Biomed. Sci. 2016; 23: 66-66. https://doi.org/10.1186/s12929-016-0285-9.

26. Górski Andrzej, Ryszard M, Jończyk-Matysiak Ewa, et al. Perspectives of PhageEukaryotic Cell Interactions to Control Epstein-Barr Virus Infections. Front. Microbiol. 2018; 630-630. https://doi.org/ 10.3389/fmicb.2018.00630.

27. Orourke J P, Peabody D S, Chackerian B. Affinity selection of epitope-based vaccines using a bacteriophage virus-like particle platform. Curr. Opin. Virol. 2015; 76-82. https://doi.org/10.1016/j.coviro.2015.03.005.

28. Zuercher A W, Miescher S M, Vogel M, et al. Oral anti-Ig E immunization with epitope-displaying phage. Eur. J. Immunol. 2015; 30: 128-135. https://doi.org/10.1002/1521-4141(200001)30:1<128::AIDIMMU128>3.0.CO;2-X.

29. Piekarowicz A, Klyz A, Majchrzak M, et al. Oral Immunization of Rabbits with S. enterica Typhimurium Expressing Neisseria gonorrhoeae Filamentous Phage Ф6 Induces Bactericidal Antibodies Against N. gonorrhoeae. Sci. Rep-Uk. 2016; 6: 22549-22549. https://doi.org/10.1038/srep22549.

30. Courtney B C, Williams K C, Schlager J J. A phage display vector with improved stability, applicability and ease of manipulation. Gene 1995; 165: 139-40. https://doi.org/10.1016/0378-1119(95)00526-C.

31. Jonas Kügler, Nieswandt S, Gerlach G F, et al. Identification of immunogenic polypeptides from a Mycoplasma hyopneumoniae genome library by phage display. Appl. Microbiol. Biotechnol. 2008; 80: 447-458. https://doi.org/10.1007/s00253-008-1576-1.

32. Krut O, Bekeredjian-Ding I. Contribution of the Immune Response to Phage Therapy. J. Immunol. 2018; 200: 3037-3044. https://doi.org/ 10.4049/jimmunol.1701745.

33. Hodyra-Stefaniak K, Miernikiewicz P, et al. Mammalian Host-Versus-Phage immune response determines phage fate in vivo. Sci. Rep-Uk. 2015; 5: 1480214802. https://doi.org/10.1038/srep14802. 


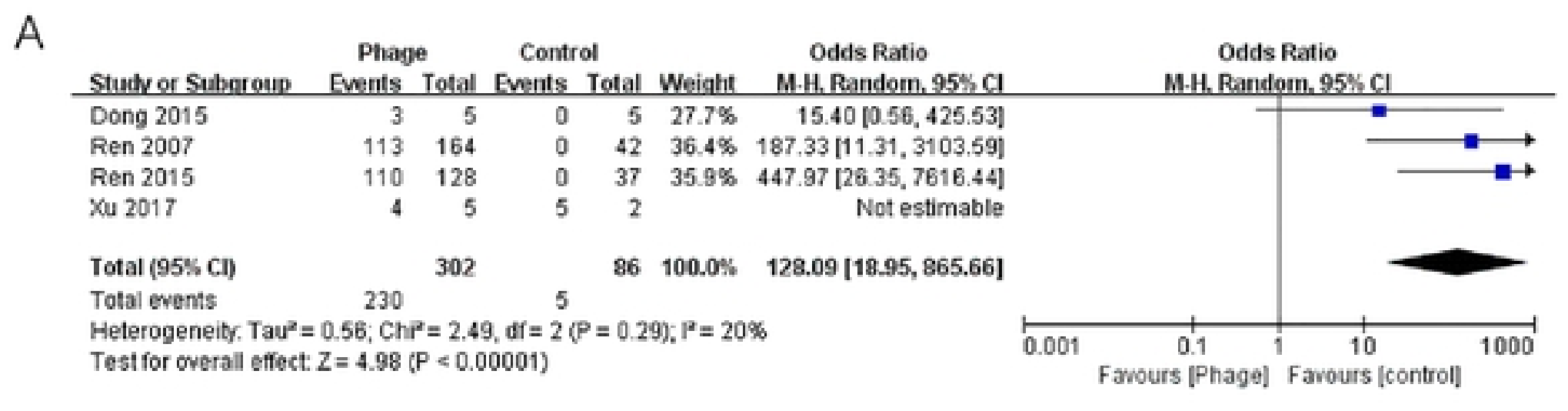

B

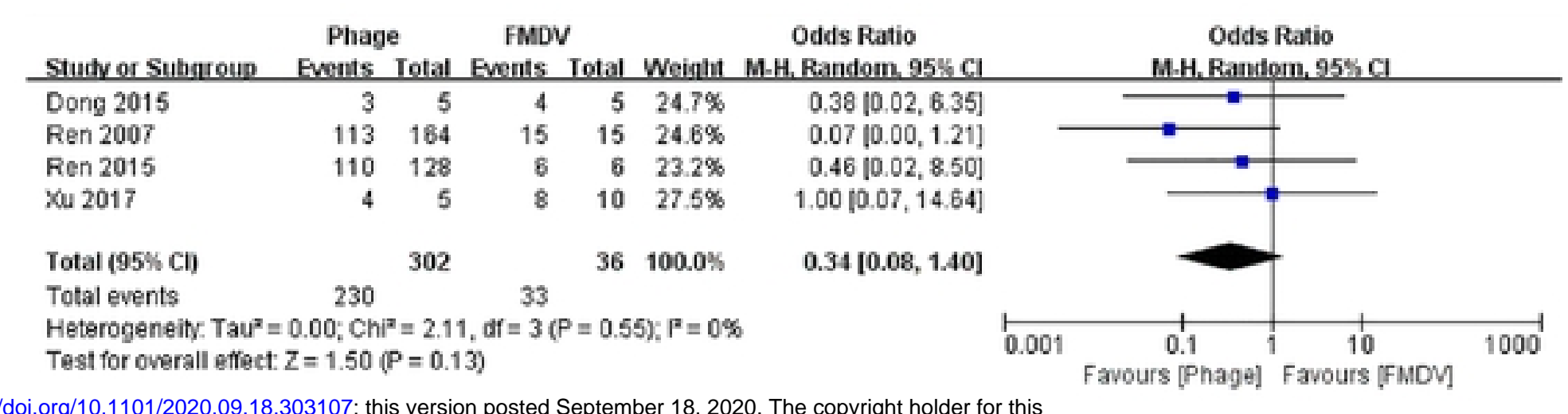

bioRxiv preprint doi: httpS://doi.org/10.1101/2020.09.18.303107; this version posted September 18, 2020. The copyright holder for this preprint (which was het certified by peer review) is the author/funder, who has granted bioRxiv a license to display the preprint in

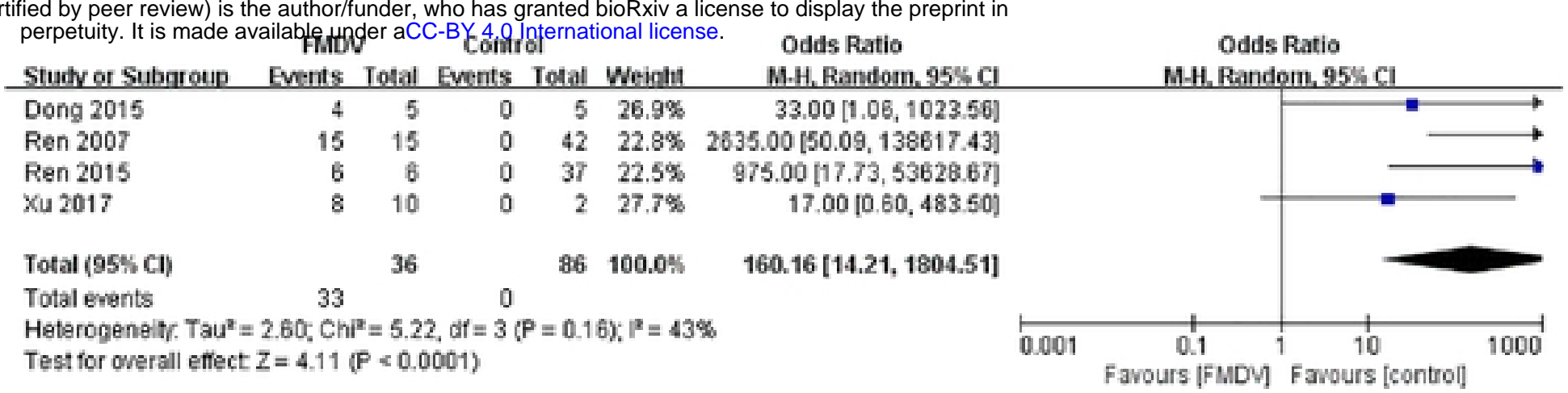




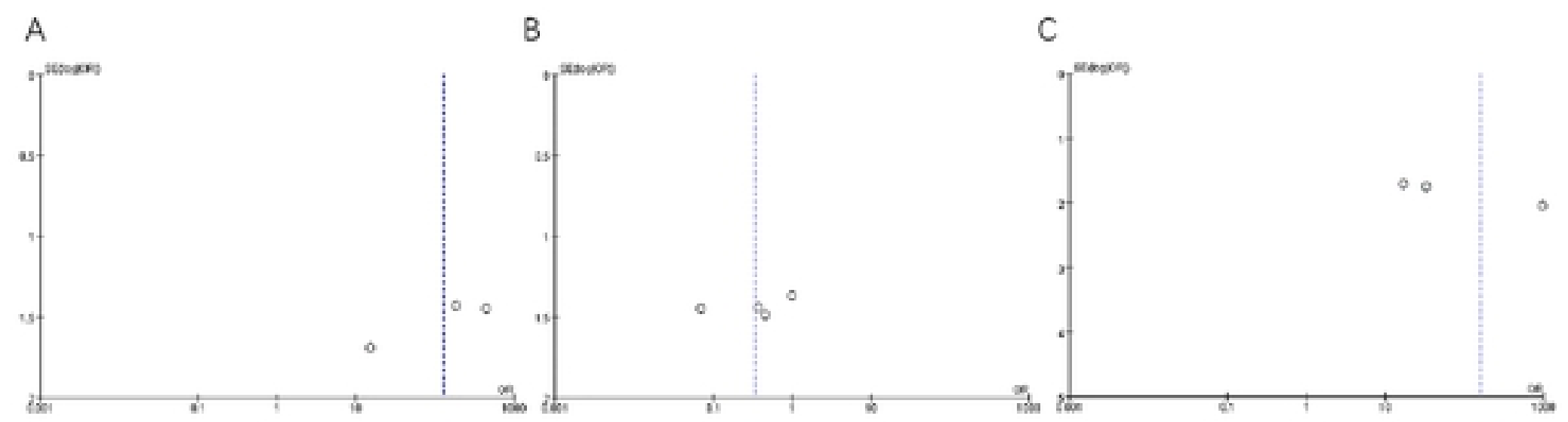

bioRxiv preprint doi: https://doi.org/10.1101/2020.09.18.303107; this version posted September 18, 2020. The copyright holder for this preprint (which was not certified by peer review) is the author/funder, who has granted bioRxiv a license to display the preprint in

Fig.3 
A

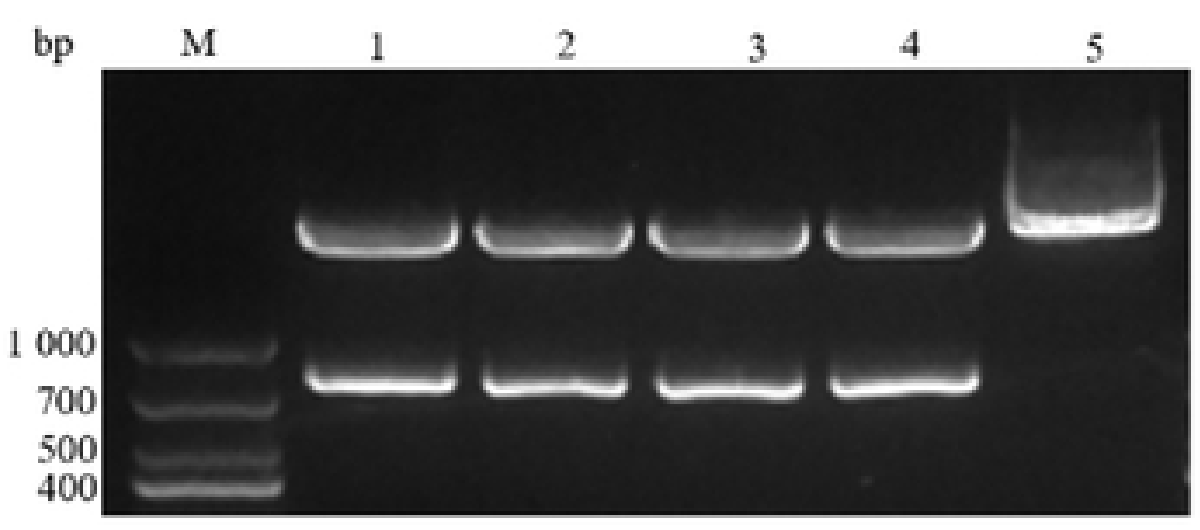

B

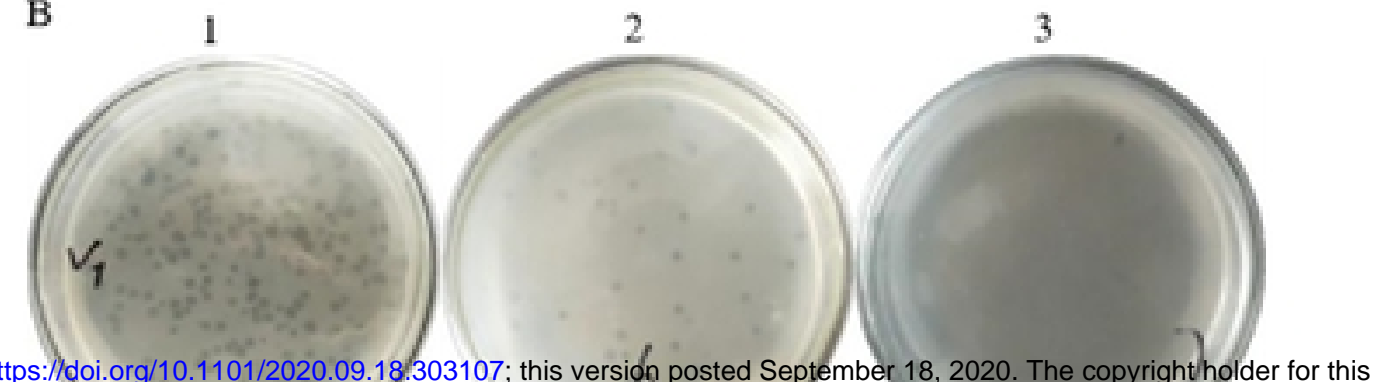

C

bioRxiv preprint doi: https://doi.org/10.1101/2020.09.18.303107; this versión posted September 18, 2020. The copyright holder for this preprint (which was not certified by peer review) is the author/funder, who has granted bioRxiv a license to display the preprint in

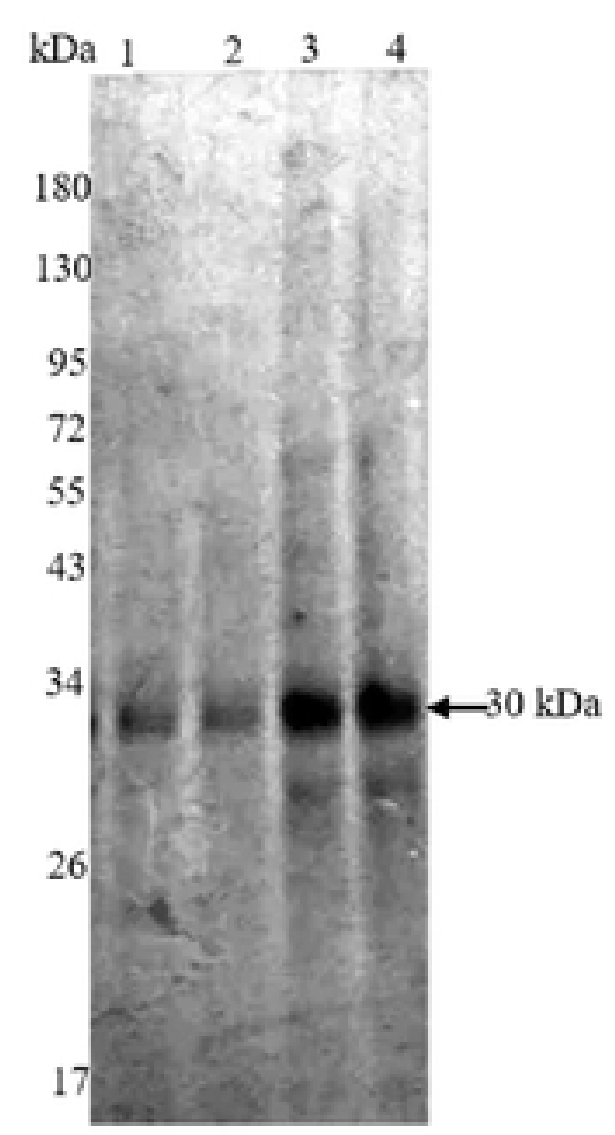

Fig.4 
A

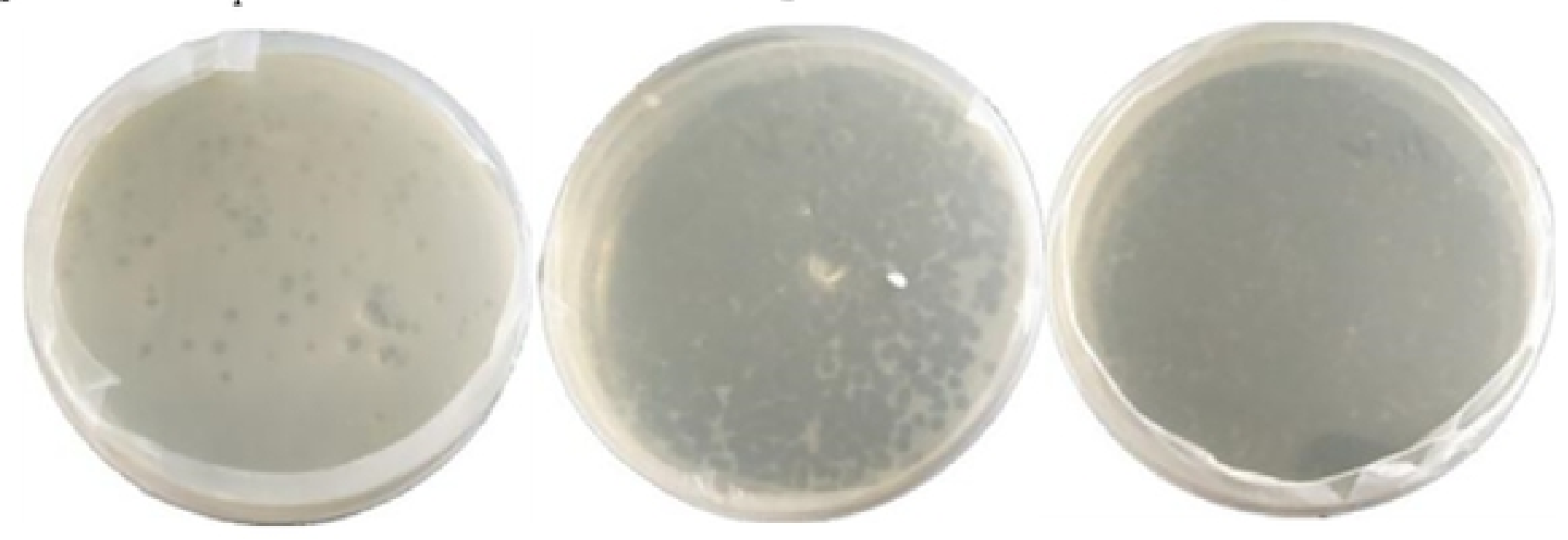

B

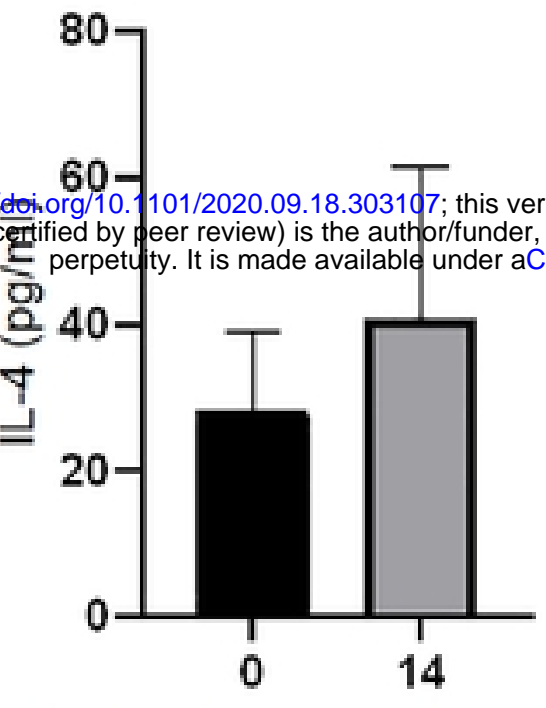

Days post primary immunization
C

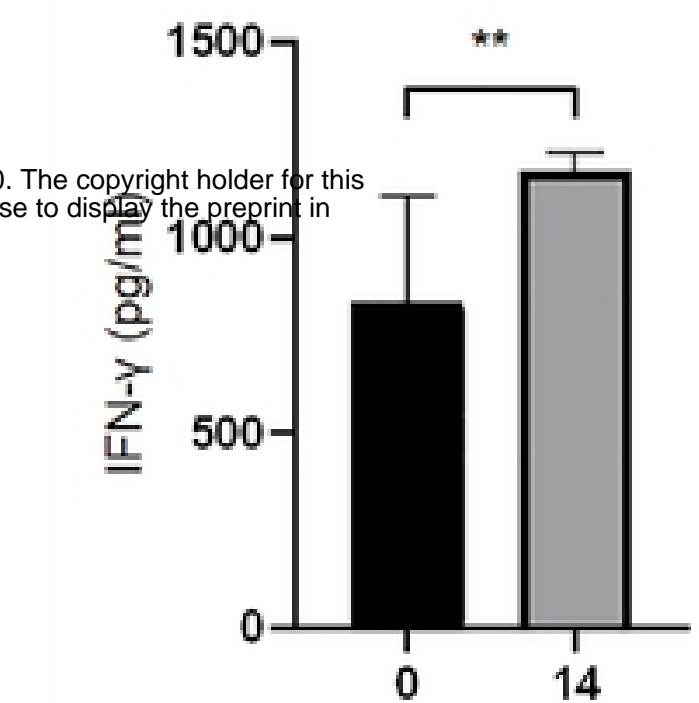

Days post primary immunization

Fig.5 

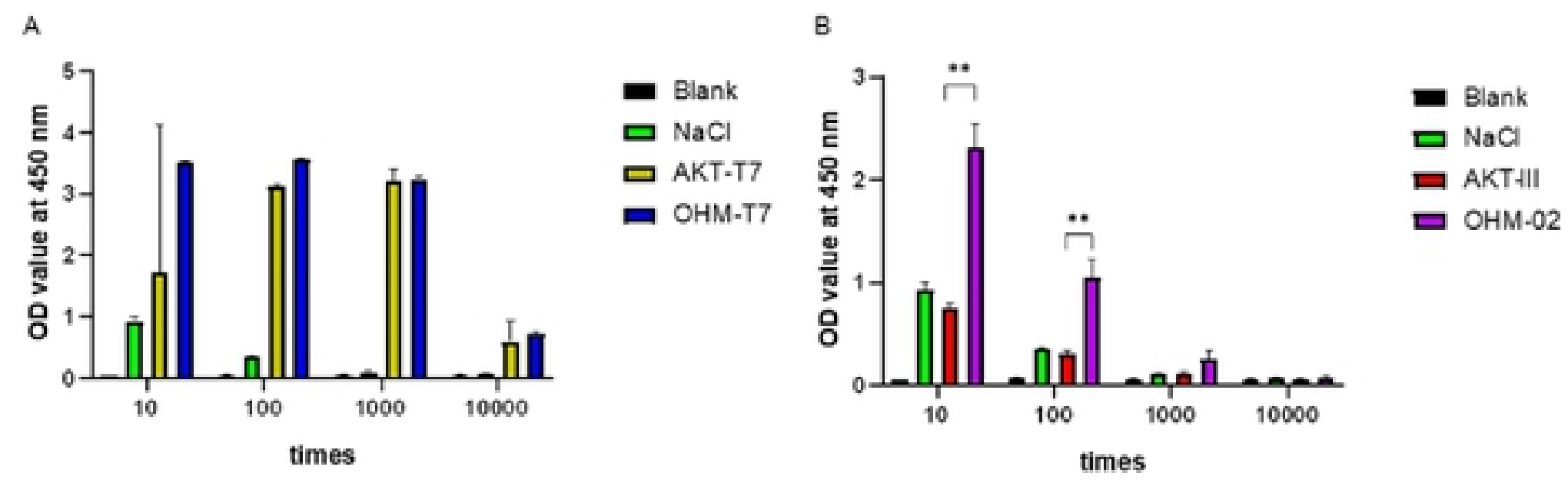

$c$

D
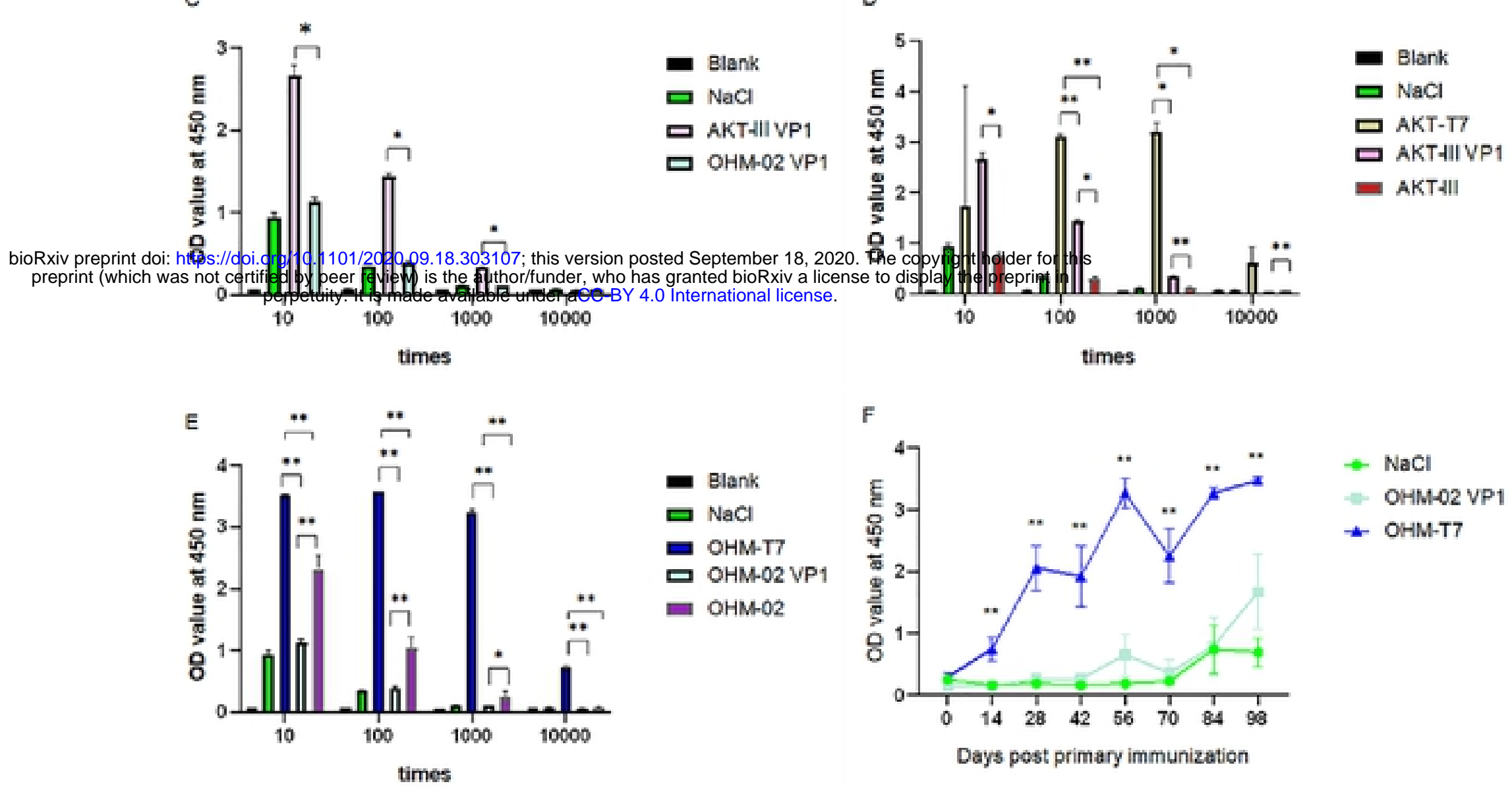

Fig.6 


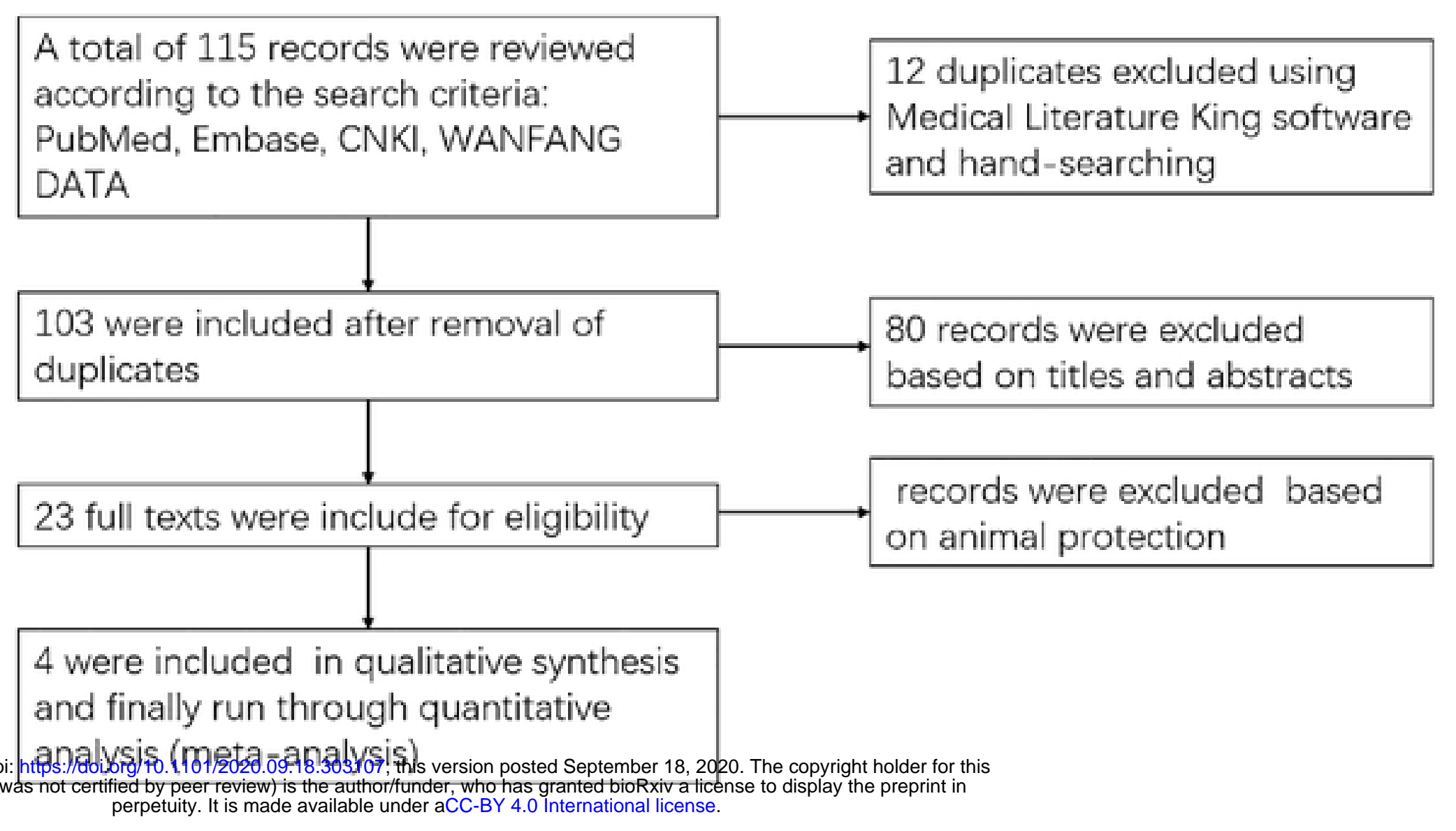

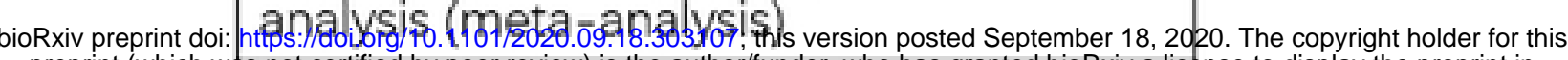
preprint (which was not certified by peer review) is the authorfunder, who has granted bioRxiv a tice.
perpetuity. It is made available under aCC-BY 4.0 International license. 